\title{
Determinants of Postnatal Care and Timing of the First Postnatal Care for Newborns in Ethiopia: Further Analysis of 2019 Ethiopian Demographic and Health Survey
}

\section{Sewnet Adem Kebede ( $\nabla$ sewnetme1@gmail.com )}

University of Gondar College of Medicine and Health Sciences https://orcid.org/0000-0001-7750-7596 Adisu Birhanu Weldesenbet

Haramaya University College of Health and Medical Sciences

Biruk Shalmeno Tusa

Haramaya University College of Health and Medical Sciences

\section{Research}

Keywords: PNC, determinant, Ethiopia, postnatal period

Posted Date: November 10th, 2021

DOI: https://doi.org/10.21203/rs.3.rs-1053057/v1

License: (c) (1) This work is licensed under a Creative Commons Attribution 4.0 International License.

Read Full License

Version of Record: A version of this preprint was published at Frontiers in Pediatrics on March 24th, 2022. See the published version at https://doi.org/10.3389/fped.2022.809643. 


\section{Abstract}

Background: Neonatal mortality remain a persisting public health challenge in Ethiopia. Most of the factors that lead to neonatal deaths could be prevented through postnatal check-ups. However, in Ethiopia, coverage of PNC continues to be low. This study aims to assess the determinant factors of PNC visit and the timing of PNC among newborns in Ethiopia.

Methods: Using the Ethiopian Mini Demographic and Health Survey (EMDHS) 2019, a total weighted sample of 2,105 women aged 15-49 giving birth in the 2 years preceding the survey was included in the study. Generalized linear mixed model were separately fitted to identify factors associated with any PNC for newborns delivered at home and health facility. Multinomial logistic regression was used to assess timing of PNC with their associated factors.

Results: Overall, only $13 \%(95 \% \mathrm{Cl} ; 11.2,14.0)$ of the newborns received PNC in Ethiopia. Among newborns delivered at home, attending any PNC were determined by region, maternal educational status and birth order. On the other hand, among newborns delivered in a health facility, region, number of ANC visit and religion were determinants of any PNC. Furthermore, attending first PNC within 48 hours after delivery was determined by region and religion. On the other hand, attending first PNC after 48 hours after delivery was determined by region number of ANC visits, maternal educational status and religion.

Conclusion: The finding of current study revealed low coverage of PNC among newborns regardless of place of delivery in Ethiopia. The study makes the following recommendation: increase community health literacy on postnatal care, encourage delivery at health facility, link community home birth with PNC. It will be more valuable if there is sharing of experience from regions which have better PNC coverage.

\section{Background}

Postnatal care (PNC) is the care given to the mother and her newborn baby immediately after the birth and extends up to six weeks (42 days) after birth $(1,2)$. PNC is important to reduce death, disability as well as missed opportunities to promote healthy behaviours in women, newborns, and children (3). Globally 2.4 million children died in the first month of life in 2019 (4). Every year in Africa, at least 870,000 newborns die in the first week after birth (3). In 2019, Sub-Saharan Africa had the highest neonatal mortality rate at 27 deaths per 1,000 live births $(5,6)$. Ethiopia is ranked fourth among the top ten countries with the highest number of newborn deaths in 2019 (6). According to the most recent Ethiopia Mini Demographic and Health Survey (EMDHS), the early newborn death rate was very high, with 30 babies dying in the first 28 days of life for every 1,000 live births (7).

The most vulnerable time for both mother and newborn are during the first six weeks after birth (Postnatal period). Health checks during this time especially the first two days after delivery are essential $(3,8)$. Approximately 7000 newborns die every day; with about a third of all neonatal deaths occurring within the first day after birth, and close to three-quarters occurring within the first week of life $(9,10)$. 
Elsewhere, literature reveals that most of the factors that lead to neonatal deaths could be prevented through postnatal check-ups $(8,11-13)$. Postnatal care for the baby is an important opportunity to check for danger signs, such as insufficient feeding, fast breathing, severe chest in-drawing, lethargy, fever, low body temperature or jaundice. Simultaneously, mothers can receive advice on how to identify and respond to these symptoms, as well as the benefits of exclusive breastfeeding and immunization (8).

The WHO recommends postnatal care within 24 hours of birth, regardless of where the baby is born. Newborns should receive at least three additional postnatal care visits by a skilled provider, on day 3 (4872 hours after birth), between day 7 and day 14, and again 6 weeks after birth (14). Globally, only 48 percent of newborns received a post-natal health check within the recommended time period (8). Postnatal care (PNC) programmes are among the weakest of all reproductive and child health programmes in Africa region (3). In Ethiopia, as in all countries, the postnatal period is often marked by specific cultural practices and socioeconomic factors and mothers and newborns spend most of this period at home $(1,3,15)$.

The 2019 EMDHS shows some improvement in the survival rates of infants and of children under age 5 in recent years. Under-five mortality rate dropped from 123 to 43 deaths per 1,000 live births between 2005 and 2019, and Neonatal mortality decreased from 39 to 29 deaths per 1,000 live births between the 2005 and 2016 EDHS, but has remained stable since the 2016 EDHS. This situation may be explained in part by the low level of PNC (34\%) (7).

As mortality among children under five declines globally, deaths among these children are more and more concentrated in the first days of life. This makes focus on newborn care more critically than ever before (8). The Ethiopian government proposed the National Newborn and Child Survival Strategy (2015-2020) aims to reduce neonatal mortality rate from $28 / 1,000$ live births to $11 / 1,000$ live births (16). If all newborns received high impact and cost-effective interventions during the postnatal period, it is estimated that neonatal mortality could be reduced to 12 per 1,000 live births. In other words, high postnatal care coverage could save up to 210,234 newborn lives a year in Ethiopia (16), and help the country to meet the Sustainable Development Goal of ending preventable deaths of newborns and children under 5 years of age by the year 2030 (17).

To increase coverage of PNC of newborn in Ethiopia, a better understanding of its determinant factors is important. The objectives of this study were to assess factors associated with any PNC for newborns and the timing of the first PNC. Understanding of such factors may help develop necessary strategies and interventions to help improve not only PNC coverage but also its timing in the most critical period (within 48 hours) and in turn increase neonatal survival chance in Ethiopia.

\section{Method}

\section{Study design, period and setting}


A community based cross-sectional study was employed in Ethiopia. The survey was conducted from March 21 to June 28, 2019, based on a nationally representative sample that provides estimates at the national and regional levels. Ethiopia is situated in the Horn of Africa with nine regional states (Tigray, Afar, Amhara, Oromia, Somalia, Benishangul-Gumuz. Southern Nations, Nationalities and Peoples Region (SNNPR), Gambella and Harari) and two city administrative councils (Addis Ababa and Dire Dawa) of administrative boundaries (7).

\section{Source and Study population}

All women aged 15-49 who had a birth in the 2 years preceding the survey in Ethiopia was the source population. The study population was all women aged 15-49 who had a birth in the 2 years preceding the survey in the selected enumeration areas in Ethiopia.

\section{Sample size and sampling procedure}

A total weighted sample of 2,105 women aged 15-49 giving birth in the 2 years preceding the survey was included in the study, with 942 delivered at home and 1,163 delivered in a health facility. The 2019 EMDHS sample was stratified and selected in two stages. Each region was stratified into urban and rural areas, yielding 21 sampling strata. To ensure that survey precision is comparable across regions, the sample allocation has been done through an equal allocation where 25 EAs are selected from eight regions. However, from the three larger regions Amhara, Oromia, and SNNP 35 EAs for each were selected. In the first stage, a total of 305 EAs (93 in urban areas and 212 in rural areas) were selected with probability proportional to EA size. In the second stage of selection, a fixed number of 30 households per cluster were selected with an equal probability systematic selection from the newly created household listing (7).

\section{Data collection procedure and variables}

After permission was granted through an online request by explaining the objective of our study, the data were accessed from the DHS program official database www.meauredhs.com. The EMDHS 2019 Individual Women's records (IR) was used and the dependent variable with its important predictors were extracted.

The outcome variables were any postnatal check-up within 6 weeks after delivery " $0=$ No PNC; and $1=$ Yes any PNC" and timing of first PNC " $0=$ No PNC", " $1>48$ hours", and " $2 \leq 48$ hours" (18). The independent variables were maternal age, region, residence, wealth index, number of ANC visit, maternal educational status, religion, birth order, sex of household head and current marital status.

\section{Statistical analysis}


The analysis was done using Stata 14 software's. Weighted values were used because weights restore the representativeness of sampled data and to take into account the sampling design effect when calculating standard error and in order to get statistics that are representative of the population of women aged 15-49 years. Separate analysis was conducted for both home delivery and facility delivery. Two generalized linear mixed model were fitted to identify factors associated any PNC for newborns, one for newborns delivered at home and the other for those delivered in a health facility. Adjusted Odds Ratio (AOR) with $95 \%$ confidence interval $(\mathrm{Cl})$ were reported and those variables with $p$ value $<0.05$ were considered as statistically significant factors associated with any PNC for newborns. Additionally, a multinomial logistic regression was used to assess timing of PNC with their associated factors. In both models, "never received any PNC" was the reference category.

\section{Results}

\section{Characteristics of study participants according to place of delivery, EMDHS 2019}

The total sample for the analysis were 2,105 newborns of which $1163(55.26 \%)$ were delivered at health facilities while 942 (44.74\%) were delivered at home. Newborns delivered at home had a higher proportion of 4 th order births $(55.74 \%)$ than newborns delivered in a health facility $(30.86 \%)$. For both home and facility births, about one thirds of the mothers were aged 25-29 at the time of birth. The proportion of newborns delivered at home were higher in Oromia and Amhara regional state of Ethiopia. The probability of delivering at home decreased with increased wealth index (Table 1). 
Table 1

Characteristics of study participants according to place of delivery in Ethiopia, 2019

\begin{tabular}{|c|c|c|c|c|c|c|}
\hline \multirow[t]{2}{*}{ Variables } & \multicolumn{2}{|c|}{ Home delivery } & \multicolumn{2}{|c|}{ Facility delivery } & \multicolumn{2}{|l|}{ Total } \\
\hline & $\%$ & $n$ & $\%$ & $\mathrm{n}$ & $\%$ & $\mathrm{n}$ \\
\hline \multicolumn{7}{|l|}{ Maternal age } \\
\hline $15-19$ & 8.18 & 77 & 8.86 & 103 & 8.56 & 180 \\
\hline $20-24$ & 19.05 & 179 & 27.72 & 322 & 23.84 & 502 \\
\hline $25-29$ & 31.52 & 297 & 29.28 & 340 & 30.28 & 637 \\
\hline $30-34$ & 20.74 & 195 & 17.52 & 204 & 18.96 & 399 \\
\hline $35-39$ & 13.29 & 125 & 11.66 & 136 & 12.39 & 261 \\
\hline $40-44$ & 6.58 & 62 & 4.29 & 50 & 5.31 & 112 \\
\hline $45-49$ & 0.65 & 6 & 0.66 & 8 & 0.66 & 14 \\
\hline \multicolumn{7}{|l|}{ Region } \\
\hline Tigray & 3.84 & 36 & 10.24 & 119 & 7.38 & 155 \\
\hline Afar & 2.21 & 21 & 0.91 & 11 & 1.49 & 32 \\
\hline Amhara & 18.52 & 174 & 22.22 & 259 & 20.56 & 433 \\
\hline Oromia & 43.31 & 408 & 35.86 & 417 & 39.19 & 825 \\
\hline Somali & 10.13 & 95 & 3.17 & 37 & 6.28 & 132 \\
\hline Benishangul & 0.75 & 7 & 1.47 & 17 & 1.15 & 24 \\
\hline SNNPR & 20.25 & 191 & 18.98 & 221 & 19.55 & 412 \\
\hline Gambella & 0.24 & 2 & 0.67 & 8 & 0.48 & 10 \\
\hline Harari & 0.18 & 2 & 0.36 & 4 & 0.28 & 6 \\
\hline Addis Ababa & 0.24 & 3 & 5.31 & 61 & 3.04 & 64 \\
\hline Dire Dawa & 0.33 & 3 & 0.81 & 9 & 0.60 & 12 \\
\hline \multicolumn{7}{|l|}{ Residence } \\
\hline Urban & 14.1 & 133 & 36.13 & 420 & 26.27 & 553 \\
\hline Rural & 85.9 & 809 & 63.87 & 743 & 73.73 & 1552 \\
\hline \multicolumn{7}{|c|}{ Number of ANC visit } \\
\hline$<4$ & 95.61 & 900 & 93.94 & 1093 & 94.69 & 1993 \\
\hline$\geq 4$ & 4.39 & 41 & 6.06 & 70 & 5.31 & 112 \\
\hline
\end{tabular}




\begin{tabular}{|c|c|c|c|c|c|c|}
\hline Variables & \multicolumn{2}{|c|}{ Home delivery } & \multicolumn{2}{|c|}{ Facility delivery } & \multicolumn{2}{|l|}{ Total } \\
\hline \multicolumn{7}{|c|}{ Maternal educational status } \\
\hline No education & 63.77 & 600 & 32.42 & 377 & 46.44 & 978 \\
\hline Primary & 34.42 & 324 & 44.38 & 516 & 39.92 & 840 \\
\hline Secondary & 1.15 & 11 & 14.72 & 171 & 8.65 & 182 \\
\hline Higher & 0.66 & 6 & 8.48 & 99 & 4.98 & 105 \\
\hline \multicolumn{7}{|l|}{ Religion } \\
\hline Orthodox & 28.33 & 267 & 41.77 & 486 & 35.76 & 753 \\
\hline Protestant & 30.95 & 291 & 23.43 & 273 & 26.79 & 564 \\
\hline Muslim & 38.44 & 362 & 34.06 & 396 & 36.02 & 758 \\
\hline Traditional & 2.28 & 21 & 0.74 & 9 & 1.43 & 30 \\
\hline \multicolumn{7}{|l|}{ Birth order } \\
\hline First & 12.35 & 116 & 32.99 & 384 & 23.75 & 450 \\
\hline Second & 17.06 & 161 & 23.43 & 272 & 20.58 & 433 \\
\hline Third & 14.85 & 140 & 12.73 & 148 & 13.68 & 288 \\
\hline Fourth and more & 55.74 & 525 & 30.86 & 359 & 41.99 & 884 \\
\hline \multicolumn{7}{|l|}{ Wealth index } \\
\hline Poorest & 38.2 & 360 & 8.63 & 100 & 21.86 & 460 \\
\hline Poorer & 25.18 & 237 & 18.27 & 212 & 21.36 & 449 \\
\hline Middle & 20.05 & 189 & 17.51 & 204 & 18.65 & 393 \\
\hline Richer & 11.85 & 112 & 21.72 & 253 & 17.30 & 365 \\
\hline Richest & 4.73 & 45 & 33.87 & 393 & 20.83 & 438 \\
\hline \multicolumn{7}{|c|}{ Current Marital status } \\
\hline Never in union & 0.61 & 6 & 0.86 & 10 & 0.75 & 16 \\
\hline Married & 94.88 & 893 & 95.16 & 1107 & 95.03 & 2000 \\
\hline Divorced & 4.51 & 43 & 3.97 & 46 & 4.21 & 89 \\
\hline
\end{tabular}

Postnatal care by place of delivery and timing of the first PNC 
Overall, only $13 \%$ ( $95 \%$ Cl; $11.2,14.0$ ) of the newborns received PNC after birth in Ethiopia. By place of delivery, (18\%) of newborns delivered in a health facility received PNC compared with (6\%) newborns delivered at home. Majority of newborns received their first PNC after 2 days for both home and health facility delivery (Figure 1).

\section{Determinants of postnatal care for newborns}

Among home delivery, newborns whose region was Oromia had 81\% [AOR=0.19;95\% Cl;0.38-0.99] lower odds of received any PNC compared to those whose region was Afar. The odds of home newborns having a PNC visit were 2.79 [AOR=2.79; $95 \% \mathrm{Cl} ; 1.41-5.05]$ times higher for newborns whose mothers completed primary education compared to those whose mothers had no education. The odds of home newborns having a PNC visit were 65\% [AOR=0.35;95\% Cl; 0.11-1.00], 62\% [AOR=0.38; 95\% Cl; 0.15-0.99] and $61 \%$ [AOR=0.39; 95\% Cl; 0.16-0.98] lower for newborns whose mother had a first order child, second order child and third order child compared to those who are fourth or higher order child respectively.

Among newborns delivered in a health facility, the odds of received any PNC for newborns whose region was Oromia, SNNPR, Harari, Adiss Ababa and Dire Dawa were 8.61, 11.7, 6.13, 5.89 and 5.98 times higher compared to those whose region was Afar. Newborns whose mothers had (4+ ANC) visits during pregnancy had $97 \%$ [AOR $=1.97 ; 95 \% \mathrm{Cl} ; 1.01-4.26]$ higher odds of having a $\mathrm{PNC}$ visit compared to newborns whose mothers had fewer than four ANC visits. Newborns whose mother was Protestant had $63 \%[\mathrm{AOR}=0.37 ; 95 \% \mathrm{Cl} ; 0.19-0.71]$ lower odds of received any PNC compared to those whose mother was Orthodox (Table 2). 
Table 2

Multivariable mixed effect logistic regression analysis of any postnatal care among newborns by place of delivery in Ethiopia, 2019

\begin{tabular}{|c|c|c|}
\hline \multirow[t]{2}{*}{ Variables } & Home delivery & Facility delivery \\
\hline & AOR $(95 \% \mathrm{Cl})$ & AOR (95\% Cl) \\
\hline \multicolumn{3}{|l|}{ Maternal age } \\
\hline $15-24$ & 1 & 1 \\
\hline $25-34$ & $0.93(0.39,2.21)$ & $0.93(0.59,1.48)$ \\
\hline $35+$ & $0.91(0.31,2.76)$ & $1.08(0.55,2.15)$ \\
\hline \multicolumn{3}{|l|}{ Region } \\
\hline Tigray & $2.73(0.41,18.55)$ & $5.14(0.99,26.4)$ \\
\hline Afar & 1 & 1 \\
\hline Amhara & $1.31(0.20,8.44)$ & $3.86(0.73,20.1)$ \\
\hline Oromia & $0.19(0.38,0.99)$ & $8.61(1.73,42.7)$ \\
\hline Somali & $0.39(0.11,1.49)$ & $2.32(0.33,16.2)$ \\
\hline Benishangul & $0.61(0.11,3.26)$ & $3.28(0.64,16.9)$ \\
\hline SNNPR & $0.49(0.08,2.96)$ & $11.7(2.30,60.3)$ \\
\hline Gambella & $1.39(0.26,7.48)$ & $4.78(0.86,26.3)$ \\
\hline Harari & $1.40(0.31,6.41)$ & $6.13(1.24,30.1)$ \\
\hline Addis Ababa & $5.96(0.21,16.6)$ & $5.89(1.17,29.6)$ \\
\hline Dire Dawa & $3.02(0.76,11.9)$ & $5.98(1.21,29.5)$ \\
\hline \multicolumn{3}{|l|}{ Residence } \\
\hline Urban & 1 & 1 \\
\hline Rural & $1.11(0.25,4.83)$ & $1.04(0.57,1.89)$ \\
\hline \multicolumn{3}{|c|}{ Number of ANC visit } \\
\hline$<4$ & 1 & 1 \\
\hline$\geq 4$ & $0.59(0.14,2.49)$ & $1.97(1.01,4.26)$ \\
\hline \multicolumn{3}{|c|}{ Maternal educational status } \\
\hline No education & 1 & 1 \\
\hline Primary & $2.79(1.41,5.05)$ & $1.06(0.67,1,67)$ \\
\hline
\end{tabular}




\begin{tabular}{|c|c|c|}
\hline \multirow[t]{2}{*}{ Variables } & Home delivery & Facility delivery \\
\hline & AOR (95\% Cl) & AOR (95\% Cl) \\
\hline Secondary & $3.17(0.67,14.9)$ & $0.93(0.49,1.73)$ \\
\hline Higher & $9.18(0.48,17.5)$ & $1,47(0.75,2.87)$ \\
\hline \multicolumn{3}{|l|}{ Religion } \\
\hline Orthodox & 1 & 1 \\
\hline Protestant & $0.72(0.18,2.85)$ & $0.37(0.19,0.71)$ \\
\hline Muslim & $0.82(0.19,2.31)$ & $0.67(0.41,1.08)$ \\
\hline \multicolumn{3}{|l|}{ Birth order } \\
\hline First & $0.35(0.11,1.00)$ & $1.15(0.63,2.14)$ \\
\hline Second & $0.38(0.15,0.99)$ & $1.34(0.77,2.33)$ \\
\hline Third & $0.39(0.16,0.98)$ & $1.18(0.66,2.12)$ \\
\hline Fourth and more & 1 & 1 \\
\hline \multicolumn{3}{|l|}{ Wealth index } \\
\hline Poorest & 1 & 1 \\
\hline Poorer & $1.32(0.62,2.84)$ & $1.45(0.67,3.12)$ \\
\hline Middle & $1.40(0.58,3.37)$ & $1.37(0.62,3.01)$ \\
\hline Richer & $1.25(0.43,3.58)$ & $0.97(0.44,2.13)$ \\
\hline Richest & $1.43(0.32,6.31)$ & $1.42(0.60,3.35)$ \\
\hline \multicolumn{3}{|c|}{ Current Marital status } \\
\hline Never in union & $0.63(0.03,11.9)$ & $3.61(0.65,20.1)$ \\
\hline Married & $0.67(0.19,2.31)$ & $1.80(0.73,4.45)$ \\
\hline Divorced & 1 & 1 \\
\hline \multicolumn{3}{|c|}{ Sex of household head } \\
\hline Male & 1 & 1 \\
\hline Female & $0.77(0.33,1.78)$ & $1.36(0.87,2.13)$ \\
\hline
\end{tabular}

ANC: Antenatal Care; AOR: Adjusted Odds Ratio Factors associated with timing of the first postnatal care 
The relative risk for attending first PNC within $\mathbf{4 8}$ hours after delivery to not attending PNC for newborns whose region was SNNPR was 4.24 [RRR $=4.24 ; 95 \% \mathrm{Cl}$; 1.47-12.2] times more likely than for newborns whose region was Afar. Newborns whose mothers was Protestant had $62 \%$ [RRR $=0.38 ; 95 \% \mathrm{Cl} ; 0.17-0.85]$ lower risk compared to those whose mother was Orthodox. The relative risk for attending first PNC after 48 hours after delivery to not attending PNC for newborns whose region was Tigray, Amhara, Oromia, SNNPR, Gambella, Harari, Addis Ababa and Dire Dawa was 3.82 [RRR=3.82; 95\% Cl; 1.26-11.5], 3.44 [RRR=3.44; 95\% Cl; 1.15-10.3], 3.64 [RRR=3.64;95\% Cl;1.29-10.2], 3.72 [RRR=3.72 ;95\% Cl;1.21-11.4], 4.12 [RRR $=4.12 ; 95 \% \mathrm{Cl} ; 1.31-12.9], 6.21$ [RRR=6.21; 95\% Cl;2.24-17.2], 7.82 [RRR=7.82; 95\% Cl; 2.62-23.4] and 6.28 [RRR $=6.28 ; 95 \% \mathrm{Cl} ; 2.27-17.4]$ times more likely than for newborns whose region was Afar. Similarly, for newborns whose mothers made (4+ ANC) visits, the relative risk for attending first PNC 48 hours after delivery versus not attending PNC was $91 \%$ [RRR $=1.91 ; 95 \% \mathrm{Cl} ; 1.07-3.79]$ higher than for newborns whose mothers made fewer than four ANC visits. Newborns to mothers who had primary education had $51 \%$ [RRR $=1.51 ; 95 \% \mathrm{Cl} ; 1.01-2.30]$ higher odds than that of newborns whose mothers had no education at all and Newborns to mothers who had higher education had 2.21 [RRR $=2.21 ; 95 \% \mathrm{Cl} ; 1.15-4,24]$ times more likely than that of newborns whose mothers had no education at all. Newborns whose mothers was Protestant had $58 \%[\mathrm{RRR}=0.42 ; 95 \% \mathrm{Cl} ; 0.23-0.79]$ lower risk compared to those whose mother was Orthodox (Table 3). 
Table 3

Factors associated with timing of the first postnatal check-ups among newborns in Ethiopia, 2019

\begin{tabular}{|c|c|c|}
\hline \multirow[t]{2}{*}{ Variable } & Within 48 hours & After 48 hours \\
\hline & $\operatorname{RRR}(95 \% \mathrm{Cl})$ & $\operatorname{RRR}(95 \% \mathrm{Cl})$ \\
\hline \multicolumn{3}{|l|}{ Maternal age } \\
\hline $15-24$ & 1 & 1 \\
\hline $25-34$ & $1.22(0.63,2.35)$ & $0.91(0.58,1.41)$ \\
\hline $35+$ & $1.13(0.45,2.77)$ & $1.08(0.57,2.06)$ \\
\hline \multicolumn{3}{|l|}{ Region } \\
\hline Tigray & $2.37(0.75,7.52)$ & $3.82(1.26,11.5)$ \\
\hline Afar & 1 & 1 \\
\hline Amhara & $1.07(0.31,3.76)$ & $3.44(1.15,10.3)$ \\
\hline Oromia & $1.17(0.38,3.59)$ & $3.64(1.29,10.2)$ \\
\hline Somali & $0.58(0.17,2.06)$ & $0.93(0.24,3.53)$ \\
\hline Benishangul & $1.69(0.58,4.92)$ & $1.54(0.46,5.08)$ \\
\hline SNNPR & $4.24(1.47,12.2)$ & $3.72(1.21,11.4)$ \\
\hline Gambella & $1.60(0.45,5.69)$ & $4.12(1.31,12.9)$ \\
\hline Harari & $0.75(0.21,2.72)$ & $6.21(2.24,17.2)$ \\
\hline Addis Ababa & $0.21(0,02,1.94)$ & $7.82(2.62,23.4)$ \\
\hline Dire Dawa & $1.27(0.39,4.06)$ & $6.28(2.27,17.4)$ \\
\hline \multicolumn{3}{|l|}{ Residence } \\
\hline Urban & 1 & 1 \\
\hline Rural & $0.74(0.41,1.35)$ & $1.12(0.71,1.78)$ \\
\hline \multicolumn{3}{|c|}{ Number of ANC visit } \\
\hline$<4$ & 1 & 1 \\
\hline$\geq 4$ & $0.87(0.26,2.87)$ & $1.91(1.07,3.79)$ \\
\hline \multicolumn{3}{|c|}{ Maternal educational status } \\
\hline No education & 1 & 1 \\
\hline Primary & $1.49(0.87,2.56)$ & $1.51(1.01,2.30)$ \\
\hline
\end{tabular}




\begin{tabular}{|lll|}
\hline Variable & Within 48 hours & After 48 hours \\
\cline { 2 - 3 } & RRR $(95 \% \mathrm{Cl})$ & RRR $(95 \% \mathrm{Cl})$ \\
\hline Secondary & $1.16(0.46,2.91)$ & $1.53(0.84,2.77)$ \\
\hline Higher & $2.04(0.75,5.47)$ & $\mathbf{2 . 2 1}(\mathbf{1 . 1 5}, 4,24)$ \\
\hline Religion & & \\
\hline Orthodox & 1 & 1 \\
\hline Protestant & $\mathbf{0 . 3 8}(0.17,0.85)$ & $\mathbf{0 . 4 2}(0.23,0.79)$ \\
\hline Muslim & $0.74(0.37,1.48)$ & $0.74(0.46,1.19)$ \\
\hline Birth order & & \\
\hline First & $0.53(0.26,1.07)$ & $1.11(0.62,1.98)$ \\
\hline Second & $0.92(0.49,1.69)$ & $0.98(0.58,1.67)$ \\
\hline Third & $0.75(0.38,1.47)$ & $0.87(0.50,1.52)$ \\
\hline Fourth and more & 1 & 1 \\
\hline Current Marital status & & 1 \\
\hline Never in union & $2.08(0.19,23.1)$ & $1.91(0.44,8.35)$ \\
\hline Married & $1.54(0.45,5.31)$ & $1.10(0.51,2.36)$ \\
\hline Divorced & 1 & 1 \\
\hline Sex of household head & & $1.04(0.67,1.62)$ \\
\hline Male & $1.72(0.96,3.07)$ & \\
\hline Female & & \\
\hline
\end{tabular}

ANC: Antenatal Care; RRR: Relative Risk Ratio

\section{Discussion}

Postnatal care appears to be the component of maternal and child care service poorly utilized despite being provided at a critical period for both the survival of mother and baby. This study aimed to identify factors associated with any postnatal care for newborns and also factors associated with the timing of the first PNC among newborns by place of delivery in Ethiopia.

The finding showed that the overall coverage of PNC for newborns was only $13 \%$ in Ethiopia. This finding is lower than a study done in India (69.1\%) (19), Gambia (26.7) (20) and Bangladesh (33\%) (21). This 
might be due to study time, study population and sample size variation. Furthermore, Cultural practice variation across the countries during postnatal period can be the reason.

By place of delivery, newborns delivered at home were less likely than those delivered at a health facility to receive PNC (6\% versus 18\%). This finding is consistent with other studies done Ethiopia (22), Zambia (23), Nigeria (24) and Nepal (25). This might be due to women who gave birth in health facility have greater opportunity for health education related to PNC services at the time of delivery and thus get access to learning about the types, benefit, and availabilities of PNC services during their stay in the health facility (26). Additionally, women who gave birth at home are part of a more traditional practice and are consequently less likely to use postnatal care services.

Region was a significant predictor of PNC visit among newborns in this study. This finding is consistent with similar studies done in Ethiopia $(27,28)$ and Gambia $(20)$. The possible justification could be the differences in health service accessibility and quality of healthcare between regions. In addition, it could be the result of sociocultural differences during postnatal period activities

This study revealed that maternal education was found to be predictor of PNC visit. The odds of home newborns having a PNC visit were 2.79 times higher for newborns whose mothers completed primary education compared to those whose mothers had no education. This finding consistent with previous studies Rwanda (29), Pakistan (30), Nepal (31) and Nigeria (24).The possible explanation for this similarity could be due to the fact that education helps to raise mothers' awareness and acceptance of new ideas, as well as give better information to other women about the use of postnatal care services for both mothers and newborns.

The number of ANC visits is an important determinant of PNC use. Our study also found that newborns whose mothers had (4+ ANC) visits during pregnancy had $97 \%$ higher odds of having a PNC visit compared to newborns whose mothers had fewer than four ANC visits. This evidence coincidence with previous studies elsewhere (31-33). One probable explanation is that ANC provides a chance for health promotion. As a result, women who attended ANC got appropriate counselling as well as greater knowledge on the advantages of postnatal care during the ANC session. Additionally, women may make birth plans in collaboration with their ANC provider, which will boost the utilization of hospital delivery and postnatal services (34).

Notably, this study found that newborns whose mother was Protestant had lower odds of received any PNC compared to those whose mother was Orthodox. Coincide similar finding were reported in Ethiopia (35). Our study also reveals that, newborns whose mother was Protestant was associated with lower odds of newborns receiving PNC either within 48 hours or after 48 hours (62\% vs $58 \%$ ).

The birth order of child showed a significant effect on PNC for newborns delivered at home. The findings of this study are opposite to studies conducted in India (19), Pakistan (30) and Ethiopia (36). It is possibly related to maternal experience of child birth. Since the association between birth order and PNC 
visit for newborn is controversial it needs further research to determine whether this birth order difference contributes to increase PNC utilization.

\section{Limitation of the study}

This study is not free from limitation. First, some potentially important cultural factors following birth that may affect PNC care was not assessed since they are not available in DHS data. Second, since EMDHS 2019 was mini-version, some important factors that may affect both utilization and timing of first PNC were not collected like media exposure, current pregnancy wanted, occupational status and health care decision making autonomy.

\section{Conclusion}

Low coverage of PNC among newborns were found regardless of place of delivery in Ethiopia. This study also demonstrates that various factors influence the utilisation and the timing of PNC for newborns. Among newborns delivered at home, attending any PNC were determined by region, maternal educational status and birth order. On the other hand, among newborns delivered in a health facility, region, number of ANC visit and religion were determinants of any PNC. Furthermore, attending first PNC within 48 hours after delivery was determined by region and religion. On the other hand, attending first PNC after 48 hours after delivery was determined by region, number of ANC visits, maternal educational status and religion. To increase PNC coverage, it is better to increase community health literacy on postnatal care and health facility delivery. To do so, health care provider better to use ANC visit as a mechanism to counsel and provide information about the benefit and availability of PNC and encourage delivery at health facility. It is better to develop and strengthen community-based service strategies to link community home birth with PNC, since PNC coverage among newborns delivered at home is very low. We also recommend sharing of experience from regions which have better PNC coverage.

\section{Abbreviations}

ANC: Antenatal Care;

AOR: Adjusted Odds Ratio;

Cl: Confidence Interval;

CSA: Central Statistics Agency;

EA: Enumeration Area;

EMDHS: Ethiopia Mini Demographic and Health Survey;

PNC: Postnatal Care 
RRR: Relative Risk Ratio

SNNPR: Southern Nation and Nationality and Peoples Region;

WHO: World Health Organization

\section{Declarations}

\section{Ethics approval and consent to participate}

The study doesn't involve the collection of information from subjects. Consent to participate is not applicable. We sent a one-page proposal abstract of the study to the DHS program office. They gave permission to access the data with reference number of 158703.

\section{Consent for publication}

Not applicable

\section{Availability of data and materials}

All necessary information's were included with in the manuscript

\section{Competing interests}

The authors declare that they have no competing interests.

\section{Funding}

The authors receive no funding for this study

\section{Authors' Contributions}

Conception of the work, design of the work, acquisition of data, analysis and interpretation of data was done by SA. Data curation, drafting the article, revising it critically for intellectual content, validation and final approval of the version to be published was done by SA, AB and BS. All authors read and approved the final manuscript.

\section{Acknowledgments}

We would like to thank the measure DHS for providing us the data and shape files for the study area. We acknowledge the preprint submitted for this manuscript.

\section{References}

1. Postnatal Care Module. 1. Postnatal Care at the Health Post and in the Community. Open University. 
2. World Health Organization. World Health Organization technical consultation on postpartum and postnatal care. 2010.

3. Warren C, Daly P, Toure L, Mongi P. Postnatal care. Opportunities for Africa's newborns Cape Town, South Africa: Partnership for maternal, newborn and child health. 2006:79-90.

4. Unicef. UN inter-agency group for child mortality estimation. Levels and trends in child mortality. 2020.

5. United Nation. World Mortality 2019: Highlights. 2019. [cited 2021 August 03]. Available from https://www.un.org/en/development/desa/population /publications/ pdf/ mortality/ WMR2019 /WMR2019_Highlights.pdf.

6. World Health Organization. Newborns: improving survival and well-being. 2020. [cited 2021 August 03]. Available from https://www.who.int/news-room/fact-sheets/ detail / newborns-reducingmortality

7. Ethiopian Public Health Institute - EPHI, Federal Ministry of Health - FMoH, ICF. Ethiopia Mini Demographic and Health Survey 2019. Addis Ababa, Ethiopia: EPHI/FMoH/ICF, 2021.

8. UNICEF. Newborn care. 2021. [cited 2021 August 03]. Available from https:// data. unicef.org/topic/maternal-health/newborn-care/

9. Devine S, Taylor G, UNICEF. Every child alive: The urgent need to end newborn deaths: Unicef; 2018.

10. Hug L, Alexander M, You D, Alkema L, for Child Ul-aG. National, regional, and global levels and trends in neonatal mortality between 1990 and 2017, with scenario-based projections to 2030: a systematic analysis. The Lancet Global Health. 2019;7(6):e710-e20.

11. Blencowe H, Cousens S, Mullany LC, Lee AC, Kerber K, Wall S, et al. Clean birth and postnatal care practices to reduce neonatal deaths from sepsis and tetanus: a systematic review and Delphi estimation of mortality effect. BMC Public Health. 2011;11(3):1-19.

12. Singh K, Brodish P, Haney E. Postnatal care by provider type and neonatal death in sub-Saharan Africa: a multilevel analysis. BMC public health. 2014;14(1):1-7.

13. Fadel SA, Ram U, Morris SK, Begum R, Shet A, Jotkar R, et al. Facility delivery, postnatal care and neonatal deaths in India: nationally-representative case-control studies. PLoS One. 2015;10(10):e0140448.

14. World Health Organization. WHO recommendations on postnatal care of the mother and newborn: World Health Organization; 2014.

15. Federal Democratic Republic of Ethiopia Ministry of Health. Postnatal Care. 2020. [cited 2021 August 04]. Available from file://C:/Users/Hp/Desktop/pnc/Textbook-Open University-HEATPostnatal\%20Care-CC\%20BY\%20NC\%20SA.pdf.

16. Health FMo. National strategy for newborn and child survival in Ethiopia (2015/16-2019/20). Federal Ministry of Health Ethiopia Addis Ababa, Ethiopia; 2015.

17. World Health Organization. SDG Target 3.2 | Newborn and child mortality. 2021. [cited 2021 August 04]. Available from https://www.who.int/data/gho/data/themes/topics/indicator-groups/ indicator- 
group-details/GHO/sdg-target-3.2-newborn-and-child-mortality .

18. Oza S, Cousens SN, Lawn JE. Estimation of daily risk of neonatal death, including the day of birth, in 186 countries in 2013: a vital-registration and modelling-based study. The Lancet Global health. 2014;2(11):e635-e44.

19. Paul P. Geographical variations in postnatal care use and associated factors in India: evidence from a cross-sectional national survey. GeoJournal. 2020:1-14.

20. Barrow A, Jobe A. Predictors of Postnatal Care Service Utilization Among Women of Childbearing Age in The Gambia: Analysis of Multiple Indicators Cluster Survey. International Journal of Women's Health. 2020;12:709.

21. Singh K, Brodish P, Chowdhury ME, Biswas TK, Kim ET, Godwin C, et al. Postnatal care for newborns in Bangladesh: The importance of health-related factors and location. Journal of global health. 2017;7(2).

22. Wudineh KG, Nigusie AA, Gesese SS, Tesu AA, Beyene FY. Postnatal care service utilization and associated factors among women who gave birth in Debretabour town, North West Ethiopia: a community- based cross-sectional study. BMC Pregnancy and Childbirth. 2018;18(1):508.

23. Chungu $C$, Makasa M, Chola M, Jacobs $C N$. Place of delivery associated with postnatal care utilization among childbearing women in Zambia. Frontiers in public health. 2018;6:94.

24. Dahiru T, Oche OM. Determinants of antenatal care, institutional delivery and postnatal care services utilization in Nigeria. Pan African medical journal. 2015;22(1).

25. Chhetri S, Shah R, Rajbanshi L. Factors associated with utilization of complete postnatal Care Service in Baglung Municipality, Nepal. International Journal of Reproductive Medicine. 2020;2020.

26. Workineh YG, Hailu DA. Factors affecting utilization of postnatal care service in Jabitena district, Amhara region, Ethiopia. Sci J Public Health. 2014;23(3):169-76.

27. Sisay MM, Geremew TT, Demlie YW, Alem AT, Beyene DK, Melak MF, et al. Spatial patterns and determinants of postnatal care use in Ethiopia: findings from the 2016 demographic and health survey. BMJ open. 2019;9(6):e025066.

28. Teshale AB, Tesema GA, Yeshaw Y, Tesema AK, Alem AZ, Liyew AM. Individual and community level factors associated with delayed first postnatal care attendance among reproductive age group women in Ethiopia. BMC Pregnancy and Childbirth. 2021;21(1):1-8.

29. Rwabufigiri BN, Mukamurigo J, Thomson DR, Hedt-Gautier BL, Semasaka JPS. Factors associated with postnatal care utilisation in Rwanda: A secondary analysis of 2010 Demographic and Health Survey data. BMC pregnancy and childbirth. 2016;16(1):1-8.

30. Yunus A, Iqbal S, Munawar R, Zakar R, Mushtaq SK, Sadaf F, et al. Determinants of postnatal care services utilization in Pakistan-insights from Pakistan demographic and health survey (PDHS) 200607. Middle-East Journal of Scientific Research. 2013;18(10):1440-7.

31. Khanal V, Adhikari M, Karkee R, Gavidia T. Factors associated with the utilisation of postnatal care services among the mothers of Nepal: analysis of Nepal demographic and health survey 2011. BMC women's health. 2014;14(1):1-13. 
32. Ndugga P, Namiyonga NK, Sebuwufu D. Determinants of early postnatal care attendance: analysis of the 2016 Uganda demographic and health survey. BMC pregnancy and childbirth. 2020;20(1):1-14.

33. Chaka EE, Abdurahman AA, Nedjat S, Majdzadeh R. Utilization and determinants of postnatal care services in Ethiopia: a systematic review and meta-analysis. Ethiopian journal of health sciences. 2019;29(1).

34. Magoma M, Requejo J, Campbell O, Cousens S, Merialdi M, Filippi V. The effectiveness of birth plans in increasing use of skilled care at delivery and postnatal care in rural T anzania: a cluster randomised trial. Tropical medicine \& international health. 2013;18(4):435-43.

35. Abota TL, TadeleAtenafu N. Postnatal care utilization and associated factors among married women in Benchi-Maji zone, Southwest Ethiopia: a community based cross-sectional study. Ethiopian journal of health sciences. 2018;28(3):267-76.

36. Yeneabat T, editor Factors associated with non-utilization of postnatal care in Ankesha Guagusa Woreda, Awi Zone, Northwest Ethiopia: a cross-sectional study. 28th Annual conference, 2016; 2016.

\section{Figures}

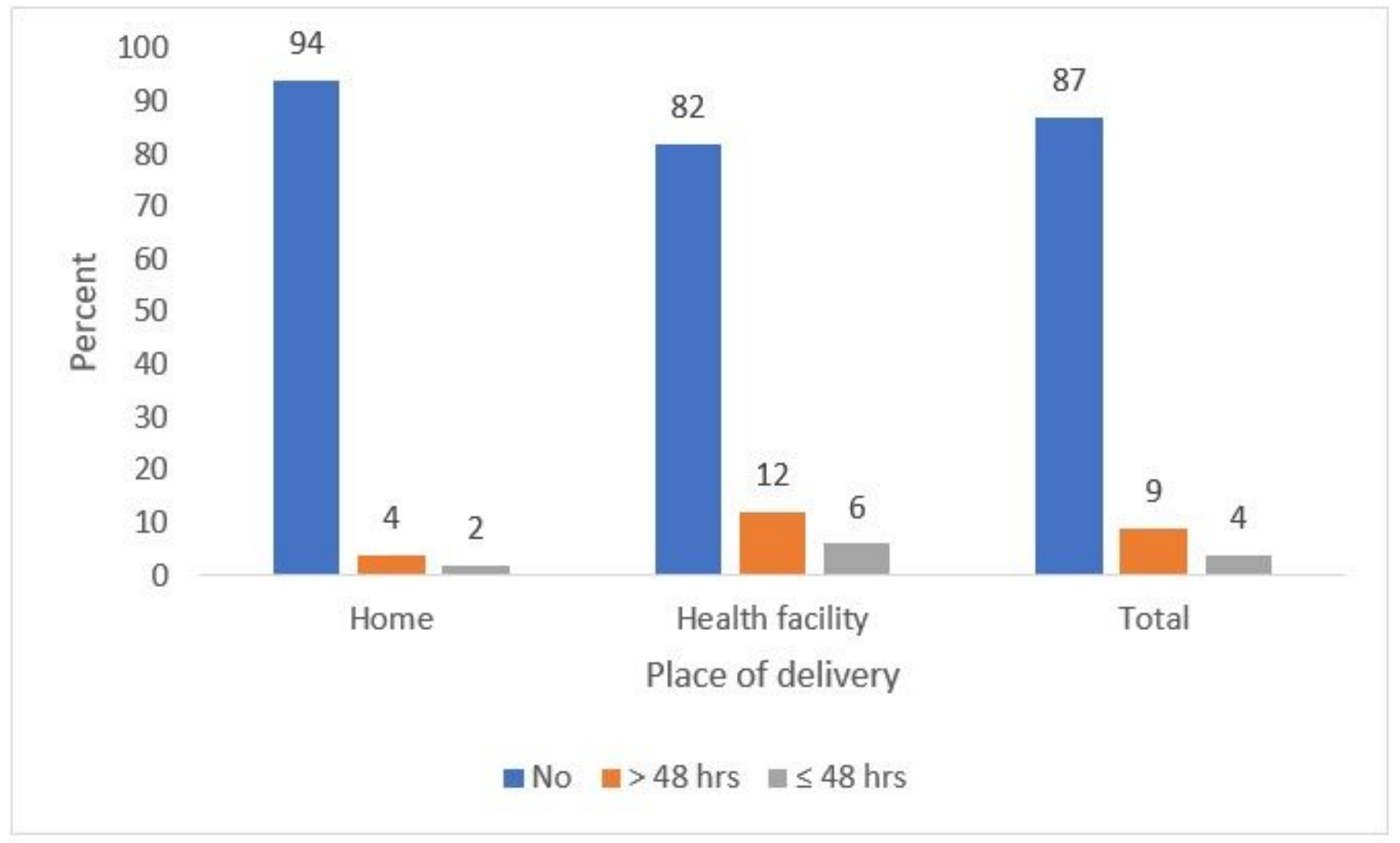

Figure 1

Percent distribution of newborns by timing of the first postnatal care 